\title{
Women: Mental Health Care Needs
}

\author{
Sunanda. G. T. ${ }^{1 *}$, Mrs. Ashwini. R. ${ }^{2}$, Dr. Eilean Lazarus Victoria ${ }^{3}$
}

\section{ABSTRACT}

Women mental health needs arise from the biological differences, life situations of women, the stresses of changing society, decreasing social support from family and community and related issues. The broader aspects of meet the needs of women mental health care must need to be strengthen the family support, increase the mental health professional interest on these issues and also sensitize the writers, media, law, policy makers regarding women's mental health care needs.

Keywords: Women, Mental Health, Changing Society, Family Support, Mental Health Professional.

The far reaching differences between men and women have inspired curiosity, poetry, romance and polemic for centuries, but only recently have they been the subjects of scrutiny by medical and social scientists. Earlier social lives of men and women used to be more predictable fitted as they were in stereotyped roles. With society in transition, options expanded for both sexes and men and women began to vary more in their roles attitudes and behaviors. Women's health and mental health in particular cannot be disassociated from the complex process the women are biologically going through, starting right from childhood through adolescence and adulthood and to old age. This requires consideration of women's mental health in broader perspective encompassing sexuality, fertility and healthy life -styles, harmonizing individual life with family life and crises interventions in situations of distress. Women mental health can be examined under the broader divisions of nature and size of women' mental health problems, the impact of psychosocial factors on the mental health of women along with the larger sociopolitical issues related to women's mental health. Among the psychosocial factors associated with mental illhealth among women are hunger, malnutrition, anemia, over work, domestic violence and impact of development projects on the life of women. Along with this women force to meet numerous demands put on during various stages of their lives in terms of choices in marriage, pregnancy,

\footnotetext{
${ }^{1}$ M.Sc (N), Assistant. professor, DIMHANS, Belgaum Road, Dharwad, India

${ }^{2}$ M.Sc, Psychology, Clinical Psychologist, DIMHANS, Belgaum Road, Dharwad. India

${ }^{3}$ Asst. Prof. College Of Nursing, Sultan Quboos University, Muscat

*Responding Author

(C) 2016, G Sunanda, R Ashwini; licensee IJIP. This is an Open Access Research distributed under the terms of the Creative Commons Attribution License (http://creativecommons.org/licenses/by/2.0), which permits unrestricted use, distribution, and reproduction in any Medium, provided the original work is properly cited.
} 
childbirth, education and employments so on, most of these choices are often not what they themselves have consented to or chosen. Women are forced to live more for others than for themselves even in places like home and family. Even when a women has no choices to decide things at home or about herself, she takes moral responsibility for situation, leading to guilty. The problem of mental health of women occurs at three levels. Firstly a large amount of mental disorders among women remains unrecognized and untreated. Secondly, there are a number of mental disorders which are disproportionately more among women. Thirdly due to social and gender inequality women receives less their proper share of benefits of mental health services. Mental health is as important as physical health. In fact, no research showing us how closely the two connected. Taking care of our mental health can help us feel better physically. And taking care of our body is important for mental health. Good mental health helps you enjoy life and cope with problems. It offers a feeling of well-being and inner strength. Just as take care of our body by eating right and exercising we can do things to help protect our mental health for that the first step is being able to recognize and talk honestly about our mental health. Women mental is important to others, because people depend on women's and their well being, mental health affects how we act with family it affects our work. Taking care of women's mental health is important to people around women.

\section{Risk factors of women's mental health problems:}

Women as a care taker: Most women's are carers to their children's, partners, parents, other relatives or friends. Women carers are more likely to suffer from anxiety or depression than the general population.

Women as guardians of family health: Traditionally women have tended to taken on responsibility of looking after the health of members of their family as well as themselves. This role makes it particularly important that women understand how the choices will make in everyday life can affect women's mental health.

\section{Women mental health is hard to talk about:}

Women comfortably talk to doctor, family friends when she is sick or hurt physically but she might prefer to keep mental health problems a secret. It is hard to see why? There is still shame associated with mental illness. Family and culture can sometimes block the way when she need help for mental health problems. Women sometimes feel uncomfortable talking about problems outside their family. In many cultures mental illness is something that we just don't' discuss. But taking care of her mental health is too important to ignores even if it embarrasses others close her.

\section{Gender issues on women mental health:}

Mental health problems affect women and men equally but some are more common among women. Treatments need to be sensitive to and reflect gender differences. Various social factors 


\section{Women: Mental Health Care Needs}

put women at risk of poor mental health because of the role and status that they typically have in society. The social factors particularly affecting women mental health includes:

- Women than men are the main career for their children and they care for others dependent relatives. Intense caring can affects emotional health, physical health, social activities and finances.

- Women's are over represented in low income, low status job's and more likely to live poverty than men.

- Women often juggle multiple roles.

- Physical and sexual abuse can have a long term impact on their mental health.

\section{Biological risks of women mental health:}

Mental health in particular cannot be disassociated from the complex process that women are biologically going through starting right from childhood through adolescence and adulthood and old age. Mental health problems can affect the girl child early in her childhood in the form of childhood sexual abuse giving rise to an increasing rate of depression and anxiety disorders. Problems related to physiological changes like premenstrual depression, menstruation itself, pregnancy and post partum blues, puerperal psychosis, stress on new born care, premenopausal syndrome, infertility, contraception issues and sexual disorders etc.

\section{Psychosocial factors:}

Women in the family who are affected the most in this constellation. Very often she is poor, malnourished, uneducated, over worked, socially deprived having poor physical health with anemia and repeated pregnancies. Epidemiological evidences is accumulating linking mental disorders with alienation, powerlessness and poverty, conditions that are most frequently experienced by women.

\section{In equality in the distribution of mental health services:}

Mental health services are very unevenly distributed. Though women constitute the largest group who need and utilize these services, they have a very little say in planning and distribution of these services unfortunately, like many other areas of society, in the field of health it is the men who take the decisions for women.

\section{Socio-political issues:}

Mental health of women cannot be studies in isolation. It has to be considered in the large sociopolitical context our times. One of the important ethical issues related to mental health of women is the current organization of health services which are perceived by women as paternalistic and hierarchical with the doctor dominating system.

\section{Issues on enrichment of women:}

Women and mental health has brought forth concepts of enrichment of women in the professional, social, personal, and political dimensions. This intricate and multifaceted need is often neglected. 


\section{Women: Mental Health Care Needs}

\section{Issues of law and women's mental health:}

Institualization of women which occurs usually when social institutions like family, marriage breakdown is another cause of concern for professional of law and mental health. Notions of autonomy, choice, female desire, and dignity, have a gender bias with the women getting a rigid and curtailing attitude from society. This aspect of law has to be examined and repackaging of law reforms has to be done for greater freedom to women ensuring women of effective and non discriminating provision of laws/justice.

\section{Women's mental health problems facts:}

Depressive disorders account for close at $41.9 \%$ of the disability from neuro-psychiatric disorders among women compared to $29.3 \%$ among men. Leading mental health problems of the older adults are depression, organic brain syndromes and dementias, a majority are women. Life time prevalence rate of violence against women ranges from $16 \%$ to $50 \%$. At least one in five women suffers rape or attempted rape in their life time. Worldwide about $10 \%$ of pregnant women and $13 \%$ of women who have just given birth experience mental disorders, primarily depression. Over view of mental disorders among women are more common mental disorders like such as depression and anxiety disorders. There are also certain types of depression that are unique to women. Some women may experience symptoms of mental disorders at times of hormone changes, such as prenatal depression, premenstrual dysphoric disorders and pre menopause related depression. When it comes to other mental disorders such as schizophrenia and bipolar disorders, eating disorders, PTSD and dementias.

\section{Warning signs of mental disorder among women's:}

Women and men can develop most of the same disorders and conditions, but may experience different symptoms, some warning signs include: Persistent sadness or feelings of hopelessness, dramatic changes in eating and sleeping patterns, Appetite and weight changes, feeling fatigue, extreme low and high mood, aches, headaches or digestive problems without clear cause, irritability, social withdrawal, suicidal thoughts, perceptual disturbances like hearing or seeing things that are not theirs, etc.

\section{Tips for women to boost up their mental health:}

1. Your mental health is important. You will not have a healthy body if you don't also take care of your mind.

2. You have to take care of yourself to take care of the people who depend on you, your strength, and your wellbeing.

3. Promote your own mental health by keeping up with people and activities you enjoy. Find support when you need it.

4. Remember that by caring for your mental health and getting help when you need it, you can enjoy life at any age.

5. Don't be afraid or ashamed to ask for help. Everyone needs help at some point.

6. Balance of mental health along with spiritual, emotional and physical health.

7. Being able to recognize and talk honestly about your mental is the first step. 
8. Being able to bounce back is part of good mental health.

9. Understand that your mental health needs to be changes throughout your life.

10. Good habits and friendships cultivation.

11. Understands the values of eating practices.

12. Develop ways to cope with stress, find positive friendship and fit in activities you enjoy in midlife.

\section{Strategies for improve women's mental health care needs:}

1. Focusing on mental health rather than mental illness.

2. Sharing of Mental health information with all individuals.

3. Strengthening of family life.

4. Organization of care programmes in the community.

5. Training in mental health for all care providers.

6. Organization of referral services for primary care personnel.

7. Involvement of NGO s for local level initiatives.

8. Professional involvement and reorientation in community care.

9. General public education towards a positive approach to mental health.

10. Policy changes including legislative changes to promote mental health in the community.

\section{CONCLUSION}

Positive mental health implies hope, optimism, happiness and faith in the moral absolutes of truth, beauty and goodness; a capacity to serve and a proper perception of the means and ends related the purpose of life. Recognizing the individuality of women, wider the women role in the traditional and modern societies represents a wide spectrum from domestic work to political leadership, pace of social change have greater impact on women metal health. Need for greater freedom in the relationships like marriages and strengthening the family are the important aspects to keeps women mentally healthy. Media and law also need to be reformed to create more primitive mental health awareness and bring legal positions in harmony with modern understanding of mental health of women, social realities and aspirations of women.

\section{Acknowledgments}

The author appreciates all those who participated in the study and helped to facilitate the research process.

\section{Conflict of Interests}

The author declared no conflict of interests.

\section{REFERENCES}

CD Sherbourne, M Dwight-Johnson, R Klap (2001), "Psychological distress, unmet need, and barriers to mental health care for women”. Women's Health Issues”, Elsevier.

(c) The International Journal of Indian Psychology, ISSN 2348-5396 (e)| ISSN: 2349-3429 (p) | 149 


\section{Women: Mental Health Care Needs}

J Battaglia, RS Epstein, (1999) "Frontier ethics: Mental health care needs and ethical dilemmas in rural communities” LW Roberts Psychiatric Services, Am Psychiatric Assoc.

K.S. Raghavan, R. Srinivasa Murthy, Rashmi Lakshminarayana. (1995) "Symposium on women and mental health” Report and recommendations, Modern printing press, Bangalore.

KD Bertakis, R Azari, LJ Helm, (2000) "Gender differences in the utilization of health care services” Journal of Family.

M M Weissman, M Olfson, (1995) "Depression in women: implications for health care research Science.

\section{Websites}

www.who.int/mental_health/prevention/genderwomen/en/ www.nimh.nih.gov/health/topics/women-and-mental-health www.ncbi.nlm.nih.gov/pubmed www.mentalhealth.org.uk/a-to-z/w/women-and-mental-health https://store.samhsa.gov/shin/content/OWH09.../OWH09-CONSUMER

How to cite this article: G Sunanda, R Ashwini (2016), Women: Mental Health Care Needs, International Journal of Indian Psychology, Volume 3, Issue 4, No. 68, ISSN:2348-5396 (e), ISSN:2349-3429 (p), DIP:18.01.206/20160304, ISBN:978-1-365-39398-3 